\title{
Germ cell dynamics in the testis of the postnatal common marmoset monkey (Callithrix jacchus)
}

\author{
S Albert, J Ehmcke, J Wistuba, K Eildermann ${ }^{1}$, R Behr ${ }^{1}$, S Schlatt and J Gromoll \\ Institute of Reproductive and Regenerative Biology, Centre of Reproductive Medicine and Andrology, University \\ of Münster, Domagkstraße 11, 48149 Münster, Germany and ${ }^{1}$ Stem Cell Biology Unit, German Primate Center, \\ Kellnerweg 4, 37077 Göttingen, Germany
}

Correspondence should be addressed to S Schlatt; Email: stefan.schlatt@ukmuenster.de

\begin{abstract}
The seminiferous epithelium in the nonhuman primate Callithrix jacchus is similarly organized to man. This monkey has therefore been used as a preclinical model for spermatogenesis and testicular stem cell physiology. However, little is known about the developmental dynamics of germ cells in the postnatal primate testis. In this study, we analyzed testes of newborn, 8-week-old, and adult marmosets employing immunohistochemistry using pluripotent stem cell and germ cell markers DDX4 (VASA), POU5F1 (OCT3/4), and TFAP2C $(A P-2 \gamma)$. Stereological and morphometric techniques were applied for quantitative analysis of germ cell populations and testicular histological changes. Quantitative RT-PCR (qRT-PCR) of testicular mRNA was applied using 16 marker genes establishing the corresponding profiles during postnatal testicular development. Testis size increased during the first 8 weeks of life with the main driver being longitudinal outgrowth of seminiferous cords. The number of DDX4-positive cells per testis doubled between birth and 8 weeks of age whereas TFAP2C- and POU5F1-positive cells remained unchanged. This increase in DDX4-expressing cells indicates dynamic growth of the differentiated A-spermatogonial population. The presence of cells expressing POU5F1 and TFAP2C after 8 weeks reveals the persistence of less differentiated germ cells. The mRNA and protein profiles determined by qRT-PCR and western blot in newborn, 8-week-old, and adult marmosets corroborated the immunohistochemical findings. In conclusion, we demonstrated the presence of distinct spermatogonial subpopulations in the primate testis exhibiting different dynamics during early testicular development. Our study demonstrates the suitability of the marmoset testis as a model for human testicular development.

Reproduction (2010) 140 733-742
\end{abstract}

\section{Introduction}

Spermatogenesis depends on a stem cell system consisting of self-renewing A-spermatogonia providing constant supply of differentiating germ cells developing into enormous quantities of haploid spermatozoa during a male's life (for review, see Ehmcke et al. (2006) and Wistuba et al. (2007)). Gonocytes are immediate descendents of primordial germ cells, which became enclosed in seminiferous cords during sex differentiation of the gonad. Gonocytes are considered a transient population of germ cells disappearing prior to the onset of spermatogenesis when spermatogonia present the only remaining premeiotic germ cell type. Owing to their close phylogenetic relationship to the human in terms of genome content, physiology, and reproduction (Li et al. 2005), common marmosets (Callithrix jacchus), similar to other nonhuman primates, are known to represent human physiology and cell biology more closely than rodent animal models, although their endocrine regulation of the human-pituitary-gonadal (HPG) axis is unusual (Henke \& Gromoll 2008). In New
World monkeys, great apes, and man, the organization and sequence of spermatogenic processes have evolved convergently. Clonal expansion of spermatogonia results in arrangements of multiple stages of spermatogenesis (Wistuba et al. 2003, Luetjens et al. 2005). A marmoset's histological appearance of the seminiferous epithelium and organization of seminiferous epithelial stages closely resemble the situation in man (Millar et al. 2000, Weinbauer et al. 2001, Kelnar et al. 2002, Sharpe et al. 2003, Wistuba et al. 2003, Luetjens et al. 2005, Mitchell et al. 2008, 2009). In addition, the marmoset shows similar reproductive phases throughout life with for primates unusually - high fertility rates permitting sufficient animal numbers for experimental studies, thus allowing for generation of unambiguous data (Millar et al. 2000). Furthermore, a transgenic marmoset line was recently created providing new future options for using the marmoset in research (Sasaki et al. 2009).

As in other primate species including the human, $A_{\text {dark }}$ and $A_{\text {pale }}$ spermatogonia are thought to represent, in the marmoset, reserve and active stem cells respectively, 
in adulthood. A $A_{\text {pale }}$ spermatogonia are considered self-renewing and function as progenitors that undergo regular divisions necessary to maintain a pool of undifferentiated germ cells, which then drive the spermatogenic progress, whereas $A_{\text {dark }}$ spermatogonia are the stem cells that function as the regenerative reserve (Ehmcke et al. 2005a, 2005b, 2006, Ehmcke \& Schlatt 2006). This hypothesis is supported by a recently published study of Mitchell et al. (2008) that demonstrated the seminiferous cords to be present in the marmoset testes at 11 weeks of gestation and exhibiting a cellular organization very similar to that seen in human fetuses. It was concluded that germ cell differentiation and proliferation in the marmoset monkey was comparable to that of the human during fetal and early postnatal life and that the process of early germ cell differentiation took place over a relatively extended period (Sharpe et al. 2003). One of the key similarities between the marmoset and the human postnatal testis is that newborn human and newborn marmoset testes contain a large population of gonocytes. These can be histologically distinguished from A-spermatogonia by their localization within the center of the seminiferous cord with no contact to the basal lamina. This gonocyte population persists until many weeks after birth (Wistuba et al. 2004, Mitchell et al. 2008). The extended presence of gonocytes after birth in marmosets and men is not observed in newborn rhesus or cynomolgous monkeys. In neonatal macaques, A-spermatogonia are the most prominent germ cell type and gonocytes are only sparsely present (Simorangkir et al. 2005) rendering the marmoset a more suitable model than other primate species for exploration of premeiotic human germ cell development. In rodents, the neonatal testis is primarily populated by gonocytes that within a few days migrate toward the basal lamina and either transit into A-spermatogonia or undergo apoptosis evoking a rapid disappearance of gonocytes from the testis (deRooij 1998, Forand et al. 2009, Wu et al. 2009).

Since marmoset-specific immunohistochemical markers for gonocytes and spermatogonial stem cells (SSCs) were established, a description of the population dynamics of premeiotic germ cells from fetal period until adulthood was recently provided (Mitchell et al. 2008). However, no quantification of cell numbers has been performed as yet providing only limited information of population dynamics of germ cells at a critical period of prepubertal testis development.

This study was designed to determine absolute changes in the population of marmoset germ cells during the early postnatal period from birth to 2 months of age applying morphometric tools for determination of absolute germ cell counts. The histological analysis was complemented by analyzing changes of testicular cell markers in both postnatal developmental stages at the mRNA and protein levels and by comparing the marker expression with the adult situation. We aimed to improve the limited knowledge of germ cell dynamics in prepubertal primate testes. Our studies provide relevant data for a better understanding of the transitory events starting with gonocytes and ending with A-spermatogonia at the time of establishment of the testicular stem cell system. Since this developmental period is poorly understood but often - for example in Klinefelter patients - presents the period of germ cell loss, our observations may be highly relevant to understand various forms of male infertility.

\section{Results}

\section{Morphometric analysis of testicular development}

Testicular development in the juvenile marmoset was evaluated at the morphometric level by measuring testicular volume, cord volume, length, and diameter (Table 1). Significant increases of all parameters were detected between both developmental time points. Regarding the cellular composition of the seminiferous cords, we observed a significant increase in volume density of germ cells as well as the relative area occupied by cords and Sertoli cells (Table 2). A small but significant enlargement of germ cell size, but not of their nuclei, was also determined.

\section{Protein expression of stem cell and germ cell markers}

Positive immunohistochemical labeling for POU5F1 was observed in the nuclei of many germ cells in the newborn testis (Fig. 1). Many cells were located at the center of the seminiferous cords apparently being gonocytes while others are located more toward the periphery. In the cross sections of 8-week-old testis fewer POU5F1-positive cells were observed. No positive cells were observed in adult testes. The same staining pattern was observed for TFAP2C (Fig. 2). Immunohistochemical detection of DDX4 revealed cytoplasmic staining in many germ cells at both developmental stages and in the adult testes (Fig. 3). In the adult testis, many differentiating germ cells up to round spermatids were positively labeled.

Quantitative morphometric analysis of germ cells positive for POU5F1, TFAP2C, or DDX4 was performed

Table 1 Changes in testicular volume and basic morphometric data of testicular tissue in newborn $(n=4)$ and 8-week-old monkey testes $(n=4)$.

\begin{tabular}{lrrl}
\hline & Newborn & 8-week-old & Significance \\
\hline Testicular volume $(\mu \mathrm{l})$ & $9.1 \pm 3.8$ & $24.6 \pm 3.3^{*}$ & $P<0.001$ \\
Interstitial volume $(\mu \mathrm{l})$ & $4.8 \pm 1.5$ & $9.4 \pm 2.9^{*}$ & $P=0.031$ \\
Cord volume $(\mu \mathrm{l})$ & $3.2 \pm 1.7$ & $11.4 \pm 2.4^{*}$ & $P=0.002$ \\
Cord length $(\mathrm{m})$ & $1.2 \pm 0.6$ & $3.7 \pm 0.6^{*}$ & $P=0.001$ \\
Cord diameter $(\mu \mathrm{m})$ & $56.6 \pm 2.3$ & $62.4 \pm 3.2^{*}$ & $P=0.026$ \\
\hline
\end{tabular}

Values are means \pm s.D. $*$ Denotes statistically significant differences $(P<0.05)$. 
Table 2 Results of the stereological and morphometric analysis of germ cells (GC) and Sertoli cells (SC) in newborn $(n=4)$ and 8-week-old $(n=4)$ monkey testes.

\begin{tabular}{lccc}
\hline & Newborn & 8-week-old & Significance \\
\hline $\begin{array}{c}\text { Area occupied by } \\
\text { GC nuclei }(\%)\end{array}$ & $3.5 \pm 1.8$ & $2.7 \pm 0.8$ & $P=0.315$ \\
$\begin{array}{c}\text { Number of GC } \\
\text { nuclei/testis }\left(10^{6}\right)\end{array}$ & $0.5 \pm 0.5$ & $1.1 \pm 0.2$ & $P=0.114$ \\
$\begin{array}{c}\text { Volume density } \\
(\mathrm{GC} / \mu \mathrm{l})\left(10^{5}\right)\end{array}$ & $2.4 \pm 1.1$ & $9.8 \pm 1.9^{*}$ & $P<0.001$ \\
$\begin{array}{c}\text { Area occupied by } \\
\text { SC nuclei }(\%)\end{array}$ & $14.2 \pm 1.7$ & $21.8 \pm 5.7^{*}$ & $P=0.042$ \\
$\begin{array}{c}\text { GC nuclear } \\
\text { diameter }(\mu \mathrm{m})\end{array}$ & $7.8 \pm 0.3$ & $8.1 \pm 0.4$ & $P=0.289$ \\
\begin{tabular}{c} 
GC diameter $(\mu \mathrm{m})$ \\
\hline
\end{tabular} & $11.1 \pm 0.7$ & $12.9 \pm 1.1^{*}$ & $P=0.027$ \\
\hline
\end{tabular}

Values are means \pm s.D. * Denotes statistically significant differences $(P<0.05)$

on newborn and 8-week-old testes. The total number of germ cells per testis approximately doubled (Fig. 4). In contrast to the observation that germ cells expressing POU5F1 or TFAP2C in the cross sections were less abundant (Figs 1 and 2), calculating absolute numbers per testis revealed that POU5F1 or TFAP2C-positive germ cells remained constant between birth and 8 weeks of age (Fig. 4). However, the absolute number of DDX4-positive germ cells was significantly higher in the 8-week-old testis compared to the newborn (Fig. 4). The increase in DDX4-positive cells paralleled the significant increase in the total number of germ cells per testis.

Determination of relative counts of single or double labeled cells after co-immunohistochemical staining for either DDX4 and TFAP2C or POU5F1 and TFAP2C (Fig. 5) in the newborn testis revealed that the $43 \%$ of the germ cells expressing TFAP2C co-expressed DDX4. The remaining 57\% expressed only TFAP2C. Furthermore, $91 \%$ of the TFAP2C-positive cells co-expressed POU5F1; $4 \%$ of the germ cells expressed TFAP2C alone; and $10 \%$ only expressed POU5F1.

Western blot analysis of DDX4, POU5F1, and TFAP2C in the newborn, 8-week-old, and adult testes showed bands of expected sizes at 73, 50, and 48-52 kDa respectively (Fig. 6). The expression of POU5F1 and TFAP2C decreased during development, whereas we have detected an extremely faint band for DDX4 in the newborn testis, which did not show up during scanning. The expression of DDX4 appeared by 8 weeks and increased in the adult testis (Fig. 6).

\section{Developmental mRNA expression patterns of stem cell and germ cell markers in the marmoset testis}

We detected significant changes in mRNA levels for 10 of the 16 marker genes selected for analysis of germ and somatic cells in the newborn, 8-week-old, and adult marmosets (Fig. 7A). Expression of stem cell markers such as POU5F1, NANOG, and SOX2 was highest in the newborn testis and was already significantly lower at 8 weeks of age. All the three markers remained detectable in the adult testes. Markers representing more differentiated stages of germ cells such as $D A Z L$ or DDX4 became significantly elevated only in the adult testis. $B O L L$, a meiotic marker, was only detectable in the adult monkey. FSHR, a Sertoli cell marker, displayed a significant increase at the age of 8 weeks.

The expression patterns of the POU5F1, TFAP2C, and $D D X 4$ genes were replotted for easier comparison (Fig. 7B). The patterns of expression were similar to the quantitative detection of protein by western blot (Fig. 6). POU5F1 mRNA expression was high, albeit displaying high individual variability in the newborn, and decreased in the 8-week-old testes and even further to still detectable levels in the adult. Similar results were observed for the TFAP2C mRNA expression levels: high in newborn, lower at 8 weeks, and lowest in adult monkeys. Different expression dynamics were detected for $D D X 4$. We observed a significant increase in expression from birth to 2 months of age and determined the highest levels in adult testes.

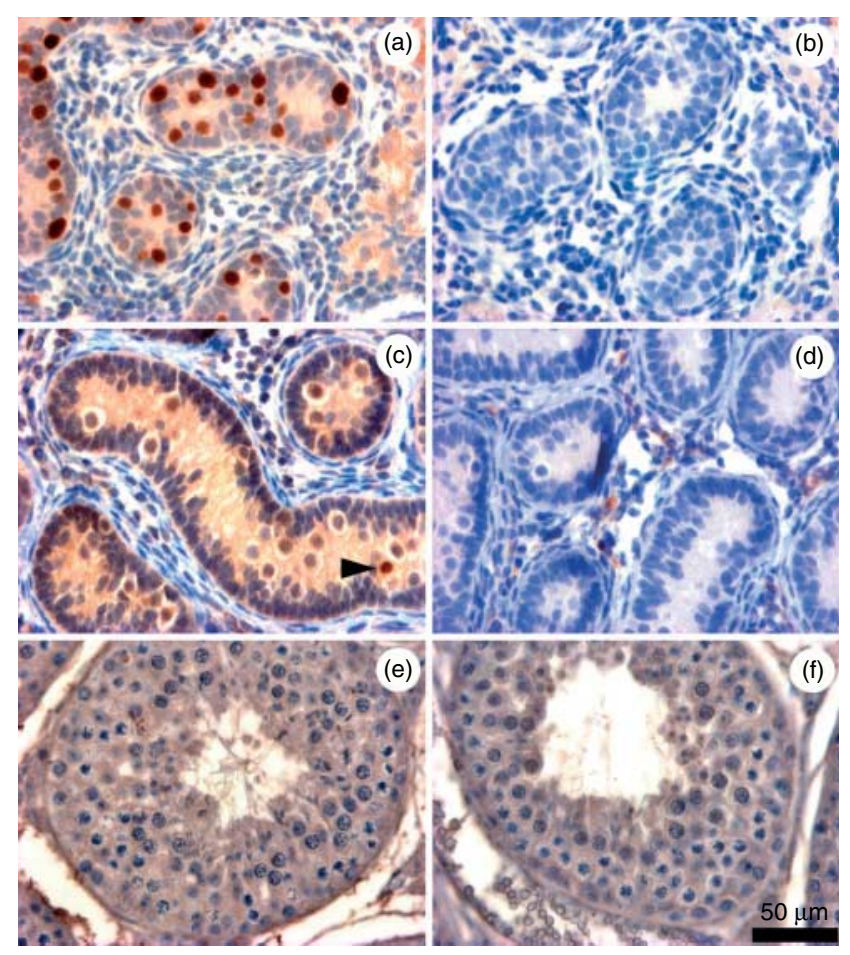

Figure 1 Micrographs showing the immunohistochemical staining of POU5F1 (nuclear). Positive staining is recognized by brown precipitates (indicated by arrowhead). The right panel depicts control stainings after omission of primary antibody. Representative areas are shown from newborn ( $a$ and b), 8-week-old (c and d), and adult (e and f) marmoset testes from a total of four testes in each group (primary magnification: $\times 25$, scale bar $=50 \mu \mathrm{m}$ ). 


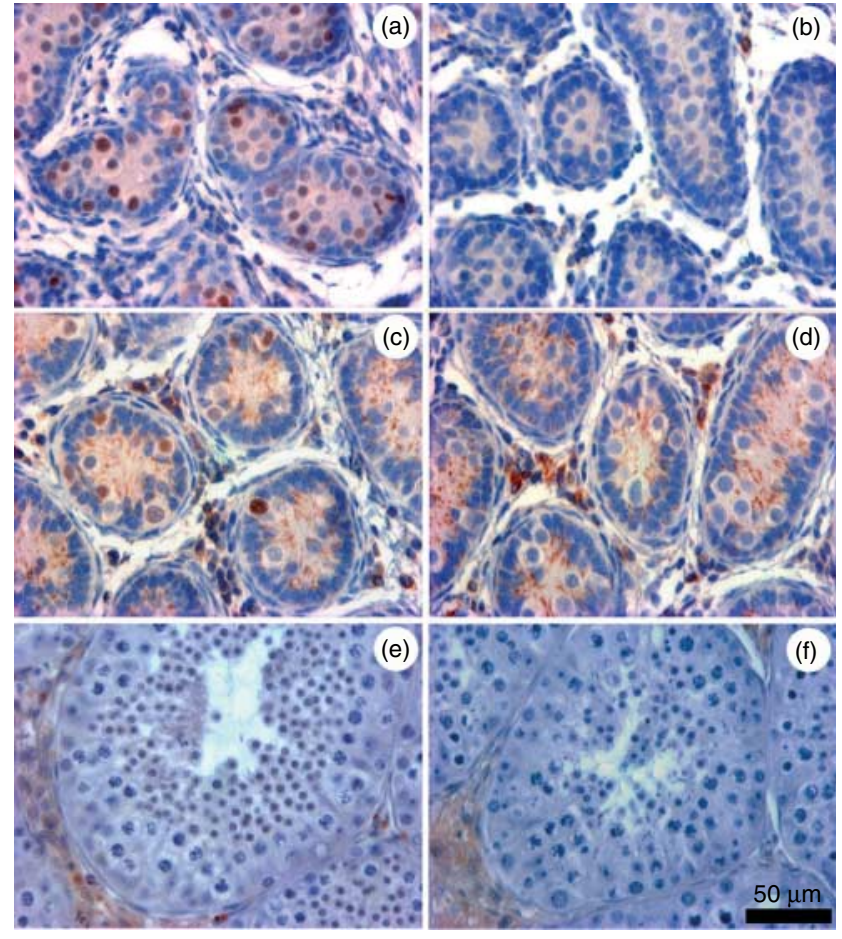

Figure 2 Micrographs showing the immunohistochemical staining of TFAP2C (nuclear). Positive staining is recognized by brown precipitates. The right panel depicts control stainings after omission of primary antibody. Representative areas are shown from newborn ( $a$ and $b$ ), 8-week-old (c and d), and adult (e and f) marmoset testes from a total of four testes in each group (primary magnification: $\times 25$; scale bar $=50 \mu \mathrm{m})$.

\section{Discussion}

The marmoset monkey is a well-accepted model in reproductive medicine (Li et al. 2005), resembling many features of human testicular development and organization (Millar et al. 2000, Weinbauer et al. 2001, Kelnar et al. 2002, Wistuba et al. 2003, Luetjens et al. 2005, Mitchell et al. 2008, 2009). A morphometric analysis of the marmoset testis demonstrated that between birth and 20 weeks of age an approximately fivefold increase in testicular weight and a tenfold increase in germ cell numbers per testis were observed (Sharpe et al. 2003). Thereafter, a rather quiescent developmental period starts, which lasts until onset of puberty and initiation of spermatogenesis. This sequence of events is very similar to the human testicular development and differs from the rather rapid and continuous series of somatic and germ cell differentiation steps occurring postnatally in rodents (Kelnar et al. 2002, Sharpe et al. 2003, Mitchell et al. 2009). These studies in marmosets revealed that the postnatal period of primate testicular development is important for the establishment of the cellular prerequisites that drive spermatogenesis later in life.

Molecular markers for testicular germ and somatic cells in the marmoset differ often from those of rodents and other primates. Therefore, the recent publications by Mitchell et al. (2008, 2009) describing immunohistochemical markers rendered it possible to identify the spermatogonial cell types in various stages of testis development and adulthood, which was an important methodological achievement. In this study, we analyzed quantitatively the population size of specific germ cell subtypes with stereological procedures using the previously described markers. Our study confirms a highly variable interindividual testicular size in newborn marmosets, which was reported previously between different litters but not between co-twins indicating an important impact of fetal conditions on the size of the testis at birth (Sharpe et al. 2003).

In the 8-week-old monkey, testicular volume was increased. Although the interstitial volume compared with the newborn testis almost doubled, the relative contribution of the testicular cord area became more prominent indicating that the main driver of testicular growth was a longitudinal outgrowth of the seminiferous cords. It is evident that the cord growth for the first 8 weeks of life is predominantly in length: the 8 -week-old monkey cords were three times longer while the cord diameter was only $10 \%$ enlarged. The density of the germ cells was four times higher in the 8-week-old testis compared with the newborn. The higher total number of germ cells reflects more densely populated and more

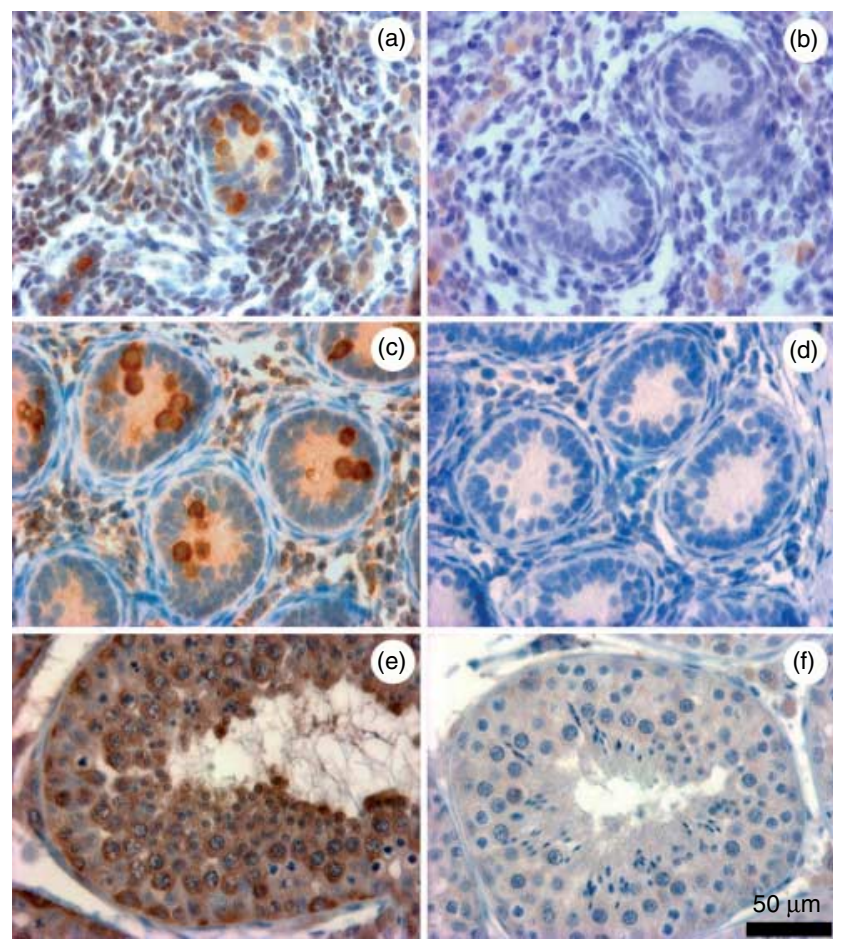

Figure 3 Micrographs showing the immunohistochemical staining of DDX4 (cytoplasmatic). Positive staining is recognized by brown precipitates. The right panel depicts control stainings after omission of primary antibody. Representative areas are shown from newborn (a and b), 8-week-old (c and d), and adult (e and f) marmoset testes from a total of four testes in each group (primary magnification: $\times 25$; scale bar $=50 \mu \mathrm{m})$. 


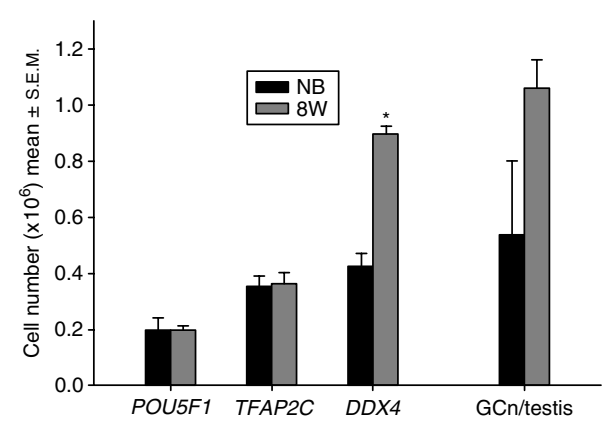

Figure 4 Results from quantitative morphometric determination of the total number of germ cells and the number of POU5F1-, TFAP2C-, and $D D X 4$-positive germ cells per testis in newborn $(\mathrm{NB}, n=4)$ and 8 -week-old $(8 \mathrm{~W}, n=4)$ marmosets. *Denotes statistically significant differences $(P<0.05)$.

extended seminiferous cords indicating that eventually two independent mechanisms may be active to expand the germ cell population: cord outgrows to extend the number of germ cell niches and germ cell proliferation to colonize the cords more densely.

Mitchell et al. (2008) suggested a change in number of cells expressing DDX4, POU5F1, and TFAP2C during development. They reported a postnatal increase in DDX4-positive germ cells and a decrease in the number of POU5F1 and TFAP2C-positive gonocytes and A-spermatogonia. In contrast to their findings, our quantitative analysis revealed a constant number of POU5F1 - and TFAP2C-expressing cells from birth to 8 weeks of age. Similar to their findings, the number of DDX4-expressing cells increased twofold between birth and 8 weeks. Although differences remain between the description of germ cell counts derived by Mitchell et al. (2008) and this study, there is consensus in that both studies corroborate the persistance of POU5F1- and TFAP2C-expressing gonocytes well beyond the immediate neonatal period. Both studies agree in their proposition that the marmoset is the more appropriate nonhuman primate model for investigating postnatal germ cell development when compared with rodents or macaques. Marmoset, similar to human, differs from rodents as its gonocytes persist beyond the first few months well into the infantile period. Unlike the macaque in which the testes appear to have advanced to a more differentiated state, marmoset and human show significant numbers of gonocytes at birth.

Previous studies applying RT-PCR to the expression of embryonic or testicular marmoset genes were based either on human or on mouse primer sequences. This carries the risk of nucleotide mismatches leading to modified amplification characteristics as well as invalid determinations when applying nonquantitative RT-PCR techniques (Müller et al. 2009, Sasaki et al. 2009). Although the marmoset genome is not yet completely annotated we circumvented the specificity problems by designing marmoset-specific primers using the already available genomic sequences accessible through trace archives (see Materials and Methods for the link to the WCBI website). Selecting suitable marker genes and retrieving the corresponding sequences from the marmoset genome enabled us to design an exoncrossing RT-PCR panel specific for the marmoset. Our new expression panel allowed evaluation of the 16 testicular genes and confirmation of our immunohistochemical findings.

The testis is a highly dynamic organ in which developmental changes in the composition of somatic or germ cell types can be traced by variations of expression levels of specific genes. However, it is important to note that after onset of spermatogenesis, when the population of germ cells represents more than $75 \%$ of the testicular mass, the contribution of germ cell mRNA in relation to total mRNA is high compared with prepubertal stages, when gonocytes and A-spermatogonia account for $<5 \%$ of the cellular
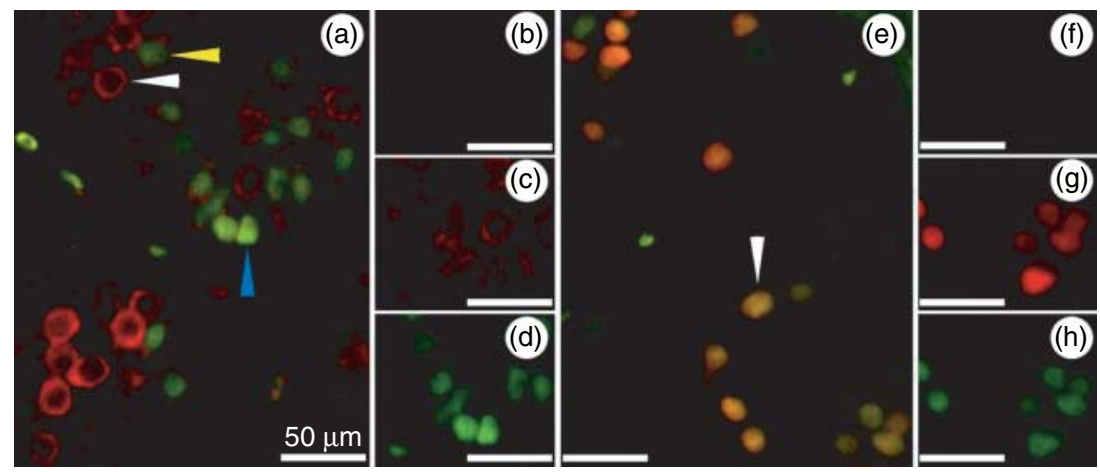

Figure 5 Micrographs showing the immunofluorescent double labeling of markers in the newborn marmoset. (a) Double staining of TFAP2C and DDX4. A blue arrowhead indicates the green nuclear TFAP2C-only expression; a white arrowhead indicates the red cytoplasmic DDX4-only staining and a yellow arrowhead indicates TFAP2C-DDX4 co-expression. (b) Negative control after omission of both primary antibodies. (c) Control: DDX4-only staining and (d) control: TFAP2C-only staining. (e) Double staining of TFAP2C-POU5F1. A white arrowhead indicates TFAP2C-POU5F1 nuclear co-expression (POU5F1 red, nuclear staining; TFAP2C green, nuclear staining). (f) Negative control after omission of both primary antibodies. (g) Control: POU5F1-only staining and (h) control: TFAP2C-only staining. Scale bar $=50 \mu \mathrm{m}$. 


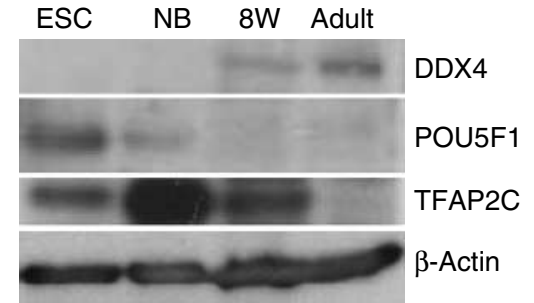

Figure 6 Western blot showing bands for DDX4 (73 kDa), POU5F1 (50 kDa), and TFAP2C (48-52 kDa). Protein samples derived from marmoset embryonic stem cell (ESC) culture, newborn (NB), 8 -week-old $(8 \mathrm{~W})$, and adult marmoset testes. The housekeeping protein $\beta$-actin $(42 \mathrm{kDa})$ and the sample derived from the ESC culture are shown as controls.

compartment and serve as the only source of germ cell mRNA. Since mRNA quantification of specific genes is always correlated to the total amount of mRNA extracted from a sample, the observed decreases in POU5F1 and TFAP2C expression from newborn to 8-week-old monkeys and the pronounced decrease in the adult monkey are primarily due to the much higher contribution of mRNA from differentiating germ cells. The decline of POU5F1 mRNA indicates that the population of a potentially pluripotent stem cell in the testis diminishes until adulthood after remaining constant during the early postnatal period.

We observed comparable changes in gene and protein expression of POU5F1 and TFAP2C revealing the persistence of a stable population of a potentially pluripotent germ cell type during early postnatal development. The observed decline of expression levels for both markers between birth and 8 weeks and even more pronounced into adulthood indicates that more differentiated populations of germ cells start to propagate, thereby diluting the mRNA transcripts and proteins extracted from the stable population of more primitive germ cells. This assumption is supported by the fact that germ cell numbers almost doubled within 8 weeks. The majority of the expanding germ cells between birth and 2 months of age were DDX4-positive indicating that the expanding population represents a more differentiated germ cell type. The final stage of this transition from undifferentiated to more differentiated germ cells is seen in the adult when expression and protein levels of DDX4 were much higher than the levels of the other more primitive germ cell markers. This was confirmed by absence of POU5F1-positive cells in the cross sections.

When evaluated in detail, the POU5F1, TFAP2C, and DDX4 immunofluorescent co-staining of the newborn testis revealed the presence of at least five different populations of undifferentiated germ cells. One population consisted of POU5F1-positive and TFAP2Cpositive cells, one population of TFAP2C-positive and DDX4-positive cells, and a third of TFAP2C-negative and DDX4-positive cells and the remaining two populations of POU5F1-positive/TFAP2C-negative and POU5F1positive/TFAP2C-positive cells. Without knowing the exact details of expansion of specific subpopulations of germ cells we can propose that a potentially pluripotent population of germ cells persist during the postnatal period while a more differentiated cohort of germ cells expands. A model to explain the dilution of the potentially pluripotent stem cells during postnatal germ cell development in marmosets is shown in Fig. 8.

In summary, our findings support the previous observations by Mitchell et al. (2008). Our additional morphometric analysis enables us to calculate the number of cells per testis indicating that despite an
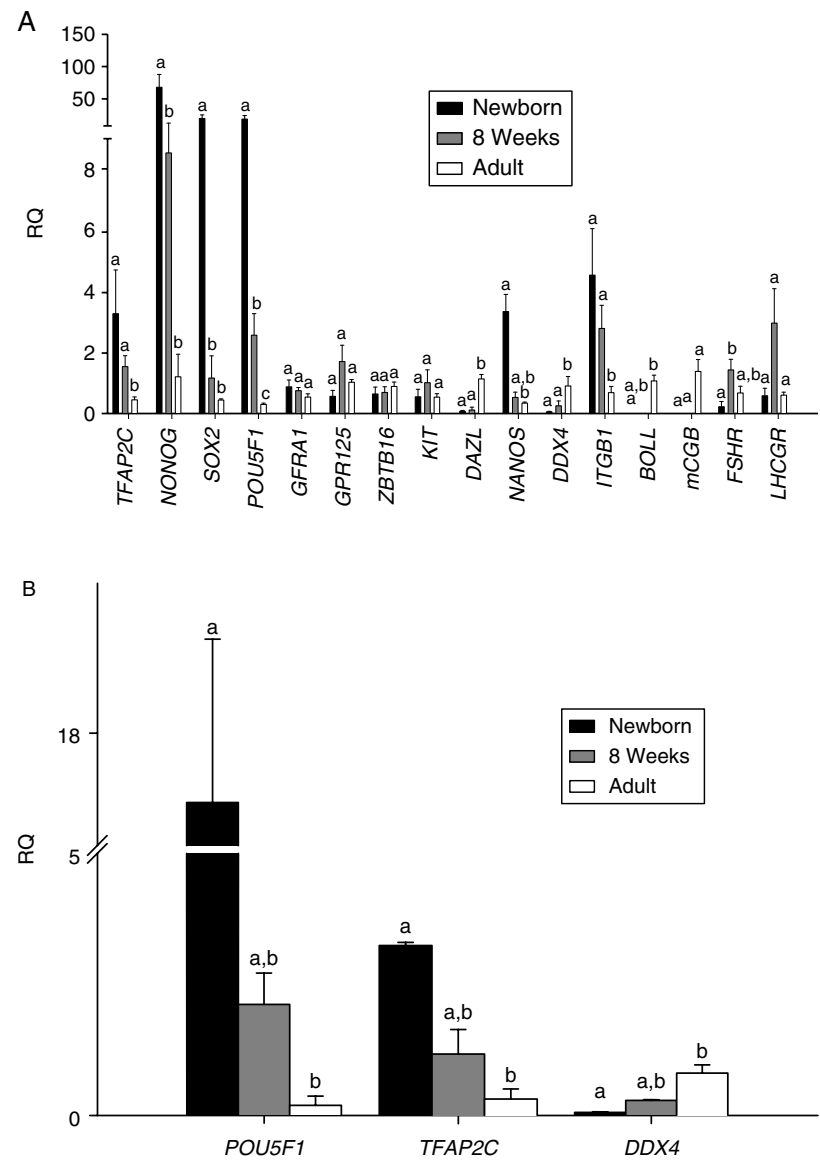

Figure 7 (A) Results obtained by relative quantitative real-time PCR. mRNA was extracted from whole testes of newborn, 8-week-old, and adult marmosets ( $n=5$ in each group). Data were plotted as relative values in relation to the expression of GAPDH and in correlation to the expression level of each marker in adult monkeys, which was set to 1 . The selected genes are listed from left to right to depict the sequence of germ cell differentiation. The relative level of mRNA expression was also evaluated for somatic testicular cells. Several pluripotency markers are found on the left followed by early germ cell markers, meiotic markers, and late spermatogenic markers. The last two markers depict Sertoli cells and Leydig cells respectively. (B) Expression pattern of POU5F1, TFAP2C, and DDX4 replotted for easier comparison.

Significant differences among ages in mRNA expression are indicated for each gene by different letters above the columns. 

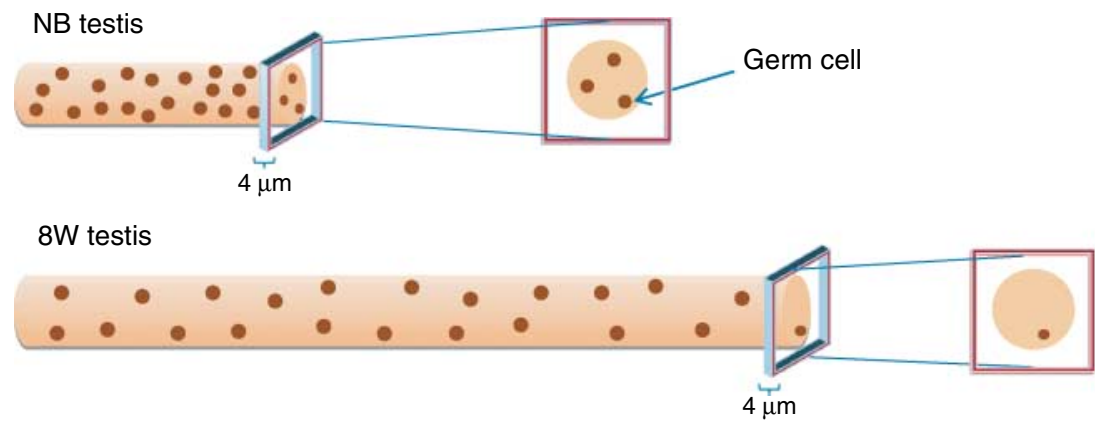

Figure 8 Schematic drawing proposing the developmental dynamic of germ cells in the newborn (NB) and 8-week-old (8W) testicular cords. The number of germ cells (brown dots) is identical in both cords shown in the diagram. Germ cells are diluted by threefold extension of the cords during the first 8 weeks of life evoking that fewer germ cells appear in any $4 \mu \mathrm{m}$ thick cross section of the testicular tissue. obvious decline of cells in tubular cross sections, the population size of POU5F1-positive germ cells remains unchanged at least for the first few weeks of life. As we showed that a threefold increase in tubular length and volume dilutes the pool of POU5F1-positive germ cells from birth to 8 weeks of age, we can now add a new and important information that germ cells in postnatal marmoset testes contain a stable pool of POU5F1positive cells while the POU5F1-negative fraction of spermatogonia is expanding. We consider this a highly important new information showing that the postnatal testis contains different cohorts of germ cells of which the POU5F1-positive germ cells are not expanding while the more differentiated DDX4-positive cells are colonizing the outgrowing cords.

\section{Materials and Methods}

\section{Animals and tissue collection}

Marmoset monkeys (C. jacchus, $n=19$ ) derived from the institutional breeding facilities were used for the study. Twelve marmosets (four newborn, four 8-week-old, and four adults) were used for histological analysis. These were anesthetized with Ketaject (equivalent to $100 \mathrm{mg} / \mathrm{ml}$ ketamine per animal) and killed by decapitation, in accordance with the German Federal Law on the Care and Use of Laboratory Animals (license No. A 924/2007; 8.87-50.10.46.09.018 Regierungspräsident Münster, LANUV NRW). Testes were dissected, weighed, and measured (length and width by callipers). One testis (right side) was snap frozen in liquid nitrogen and stored at $-80^{\circ} \mathrm{C}$ for subsequent RNA extraction and the other was fixed in $4 \%(\mathrm{w} / \mathrm{v})$ paraformaldehyde (PFA) for immunostaining. The remaining seven animals were used for RNA analysis and western blotting. They were killed by exsanguination under deep ketamine anesthesia. Their testes were quickly dissected and snap frozen in liquid nitrogen.

\section{Tissue processing}

For immunohistochemistry, PFA-fixed testicular tissue was embedded in paraffin, sectioned to $4 \mu \mathrm{m}$ thickness, and stained as indicated below. The antigens analyzed were DDX4 (Abcam, Cambridge, FL, USA, cat. no. ab13840; dilution
1:100), POU5F1 (H-134, Santa Cruz, Heidelberg, Germany, cat. no. sc-9081; dilution 1:100), TFAP2C (Santa Cruz, cat. no. sc-12762; dilution 1:50), and KIT (c-KIT) (C-19, Santa Cruz, cat. no. sc-168; dilution 1:100) with the appropriate biotinylated secondary antibodies: goat anti-rabbit (Sigma, cat. no. B7389) and goat anti-mouse (Sigma, cat. no. B7264).

Briefly, sections were dewaxed in xylene, rehydrated in graded alcohol, and washed in tap water. All slides underwent antigen retrieval by heating for $40 \mathrm{~min}$ in a steam cooker in $0.01 \mathrm{M}$ citrate buffer ( $\mathrm{pH}$ 6.0) as described previously (Norton et al. 1994). Sections were treated with $3 \%(\mathrm{v} / \mathrm{v}) \mathrm{H}_{2} \mathrm{O}_{2}$ in distilled water, rinsed with distilled water, and washed in Trisbuffered saline (TBS; $0.05 \mathrm{M}$ Tris and $0.85 \%(\mathrm{w} / \mathrm{v}) \mathrm{NaCl}, \mathrm{pH}$ 7.6). Sections were blocked for unspecific binding with goat serum diluted 1:4 in TBS containing 0.5\% (w/v) BSA (Sigma, cat. no. A9647) for $30 \mathrm{~min}$. For the staining with TFAP2C the goat serum was diluted $1: 20$ in TBS containing $0.1 \%(\mathrm{w} / \mathrm{v})$ BSA. The slides were incubated overnight with the primary antibody at $4{ }^{\circ} \mathrm{C}$ in a humidified chamber. Sections were washed three times for $5 \mathrm{~min}$ with TBS and incubated for $1 \mathrm{~h}$ with the biotinylated secondary antibody diluted 1:100 in goat serum $(5 \% \mathrm{v} / \mathrm{v})$ at $4{ }^{\circ} \mathrm{C}$ in the humidified chamber. This was followed by two further $5 \mathrm{~min}$ washes in TBS and incubation for $30 \mathrm{~min}$ with streptavidin-HRP at 1:500 (Sigma, cat. no. S5512), diluted in TBS. Positive cells were visualized by 3,3'-diaminobenzidine (Sigma, cat. no. D4168) and sections were counterstained with hematoxylin, dehydrated in graded alcohol, and immersed in xylene before mounting with Merckoglass (Merck). For each experiment, a negative control was included, in which the primary antibody had been omitted. Images were captured using an Axioskop connected to an Axiocam (Carl Zeiss, Inc., Oberkochen, Germany).

\section{Immunofluorescence}

For the immunofluorescence staining, the TFAP2C and POU5F1 antibodies were diluted 1:50 while the DDX4 antibody was diluted 1:100. Sections were initially treated as described for immunohistochemical analysis. Antigen retrieval was required for all experiments and normal goat serum $(5 \%(\mathrm{v} / \mathrm{v})$ in TBS and $0.1 \%(\mathrm{w} / \mathrm{v}) \mathrm{BSA})$ was used for blocking and dilution of the antibodies. For the double staining, TFAP2C-POU5F1 and TFAP2C-DDX4 were simultaneously incubated overnight at $4{ }^{\circ} \mathrm{C}$. Following the incubation with 
primary antibodies, sections were incubated $1 \mathrm{~h}$ at room temperature with fluorescence-conjugated secondary antibodies: goat anti-mouse Alexa 488 (Invitrogen, cat. no. A11001; diluted 1:100) for TFAP2C and goat anti-rabbit Alexa 546 (Invitrogen, cat. no. A11035; diluted 1:100) for POU5F1 and DDX4. The slides were finally mounted with Vectashield with DAPI (Vectashield mounting medium for fluorescence cat. no. H-1200, Vector Laboratories, Inc., Burlingame, CA, USA) for the nuclear counterstain. Images were captured with an Olympus BX-61 microscope (Olympus, Melville, NY, USA) and a QImaging RETIGA 4000R camera (QImaging, Burnaby, BC, Canada) and analyzed with the softwares QCapture 2.73 (Quantitative Imaging Corporation 2005) and Northern Eclipse (Empix Imaging, Inc., Cheektowaga, NY, USA) and were processed using Adobe 138 Photoshop CS2 9.0 (Adobe Systems, Inc.). Two hundred positive cells per testis were counted from three different newborn and three different 8 -week-old monkeys. From the 200 cells (set as 100\%), the percentage of singularly or co-expressing cells were calculated.

\section{Morphometric analysis of histological features and immunostained germ cells}

Several quantification methods were used to monitor the testicular development of morphometric parameters such as testicular cord size, germ cell number, and germ cell density in the testes of four newborn and four 8-week-old monkeys.

For morphometric analysis of histological features and immunohistochemical stainings each section was screened systematically starting from a random starting point and covering the entire cross-sectional area without overlap. The visual analysis consisted of the selection of about 60 fields with an area of $38086 \mu \mathrm{m}^{2}$ per field (primary objective magnification: $\times 63$ ). Two to three cross sections from two independent areas of each testis were evaluated to obtain morphometric data from each individual monkey. For analysis of immunostaining in germ cells, the cells were recognized by their uniform round nuclear shape. Once identified, the total number and the number of immunopositive GCs per viewing field were counted, and the percentage of stained and nonstained cells were recorded for each of the three antibodies. At a random base, a second person repeated the counting procedures and the results obtained were found to be in good agreement. Counting was only performed in newborn and 8-week-old, but not in adult, monkey testes, because only DDX4-positive cells were detectable in the adult monkey testis. Both SSC markers, POU5F1 and TFAP2C, were not detected in cross section of adult marmosets.

To obtain the absolute cord volume, a point-counting analysis was applied in which the percentage of the testicular area occupied by cords was calculated from a total of 99 points per field. The absolute volume of the cord area was calculated from the testicular volume and the relative contribution determined by point counting. Considering the germ cells (GC) as a perfect sphere (volume $4 / 3 \pi \times r^{3}$ ), measurement of the nuclear diameter permits calculation of its volume. The total germ cell number in the testis was obtained by point counting, determining the percentage of testicular area occupied by the GC nuclei (GC density) and dividing it by the volume of one GC nucleus ((vol.GCs $(\mu \mathrm{l}) / \operatorname{vol} .1 \mathrm{GC}(\mathrm{fl}))$ $\left.\times 10^{9}\right)$, which was measured independently in 44 individual germ cell nuclei per monkey under high primary magnification ( $\times 63)$. The diameter of all the germ cells was determined in order to see whether there were differences in the shape and size of antigen-expressing and antigen nonexpressing germ cells during testicular development. Measurements of cord parameter and GC diameters were performed using the Axiovision software (Carl Zeiss, Inc.).

The cord size was calculated from independent measurements of the cord diameter in nearly round seminiferous tubular cross sections ( $n=20$ per monkey). The length of the cords was estimated by using the formula for the height of a cylinder: $h=v /\left(\pi \times r^{2}\right)$, where $h$ represents the length of the cord, $v$ the volume of the cords, and $r$ the radius of the cord section.

\section{Western blot analysis}

Proteins from $\sim 50 \mathrm{mg}$ testis tissue were isolated using the RNeasy mini kit from Qiagen (Appendix F in the Handbook describes the protein precipitation from buffer RLT lysates). Protein precipitate was dissolved in $200 \mu$ I RIPA 2 resuspension buffer $(0.15 \mathrm{M} \mathrm{NaCl}, 15 \mathrm{NP}-40,1 \%$ LDS, 2\% SARKOSYL $(\mathrm{N}$-lauroylsacosin-natriumsalt)). For western blot analysis, 15-20 $\mu$ protein lysate (including $10 \times$ DTT and $4 \times$ loading buffer) and $5 \mu \mathrm{l}$ Novex sharp prestained protein standard from Invitrogen were loaded into an SDS gel to separate proteins in an SDS-PAGE. Proteins were then transferred to a PVDF membrane (Millipore Immobilon-P transfer membrane) using semidry electrophoresis. The membrane was washed in PBS-T $(1 \times$ PBS with $0.1 \%(v / v)$ Tween-20) and blocked for $30 \mathrm{~min}$ in $5 \%(\mathrm{w} / \mathrm{v})$ skimmed milk powder in PBS-T. Primary antibody incubation was performed for $1 \mathrm{~h}$ at room temperature or overnight at $4{ }^{\circ} \mathrm{C}$ (TFAP2C, 1:100). All antibodies were diluted in 5\% (w/v) skimmed milk powder in PBS-T and 1:1000 goat serum. The antibodies rabbit anti-POU5F1 (Santa Cruz, sc-9081; dilution 1:500), rabbit anti-DDX4 (Abcam, ab13840; dilution 1:500) mouse anti- $\beta$-actin (Sigma, A1978; dilution 1:1000), and mouse anti-TFAP2C (Santa Cruz, sc-12762) were used. After washing in PBS-T, the membrane was incubated with a secondary HRP-conjugated antibody (goat anti-rabbit HRP from Santa Cruz (cat no sc-2054) or goat anti-mouse HRP from R\&D Systems (cat. no. HAF007, Wiesbaden-Nordenstadt, Germany)). Signal detection was carried out using the ECL kit from Amersham (cat. no. RPN2209) and an Ecomax X-ray film developer.

\section{Selection of cellular markers}

For mRNA analysis, specific marker genes were chosen, which are informative for different developmental stages of germ and somatic cells. The choice of protein markers for immunohistochemistry was made on the basis of a previous publication (Mitchell et al. 2008) and we used marker genes for spermatogonial stem cells/undifferentiated spermatogonia, such as activation protein 2- $\gamma$ (TFAP2C), octamer-binding protein 3/4 (POU5F1), NANOG, SRY-box 2 (SOX2), and GDNF family receptor $\alpha-1$ (GFRA1). Tyrosine kinase receptor $K I T(K I T)$ 
Table 3 Marmoset-specific primers for relative qRT-PCR analysis.

\begin{tabular}{|c|c|}
\hline \multirow[t]{2}{*}{ TFAP2C } & F: CGACATGGCCCACCAGAT \\
\hline & R: GGGAGGTTCAGAGGGTTCTTG \\
\hline \multirow[t]{2}{*}{ NANOG } & F: AACTGGCCAAAGAATAGCAATGA \\
\hline & R: GTAGGAAGAGTAGAGGCTGGGATAGG \\
\hline \multirow[t]{2}{*}{ SOX2 } & F: GAGAACCCCAAGATGCACAAC \\
\hline & R: TCTCGGACAGCAGCTTCCA \\
\hline \multirow[t]{2}{*}{ POU5F1 } & F: AAACCCACACTTCAGCAGATCA \\
\hline & R: CACACGGACCACATCCTTCTC \\
\hline \multirow[t]{2}{*}{ GFRA1 } & F: AGGACTССТGCAAGACAAATTACA \\
\hline & R: TGGCTGGCAGTTGGTAAAAAA \\
\hline \multirow[t]{2}{*}{ GPR125 } & F: CCGCAGCAGCGAACATTA \\
\hline & R: CACGCCATCCAGCAATAGG \\
\hline \multirow[t]{2}{*}{ ZBTB16 } & F: GAGACGCACAGACAGACCCATA \\
\hline & R: TCCCACACAGCAGGCAGAA \\
\hline \multirow[t]{2}{*}{ KIT } & F: AGGAGTCTTCCTGCAGCGATAGT \\
\hline & R: TCCTTTTCTCGGCCTTGGTT \\
\hline \multirow[t]{2}{*}{$D A Z L$} & F: AATGAATGCTCAGTTTGTGAAGCT \\
\hline & R: GCTTCGGTCCACAGATTTCTTT \\
\hline \multirow[t]{2}{*}{ NANOS } & F: TGCAGGTGTGCGTGTTCTG \\
\hline & R: TGAGGATGTGGGTGGTGTAGAG \\
\hline \multirow[t]{2}{*}{$D D \times 4$} & F: AAGTATTAACAGATGCTCAACAGGATGT \\
\hline & R: TGAAGCCAGGAATGTATGCACTA \\
\hline \multirow[t]{2}{*}{ ITGB1 } & F: ACCCGGCTGCTGGTGTT \\
\hline & R: GCCACCAAGTTTCCCATCTC \\
\hline \multirow{2}{*}{$B O L L$} & F: TTTATGCTCCAAGTGCCATCAC \\
\hline & R: GCTCCTCACTGTTTTAATTGGTTCA \\
\hline \multirow[t]{2}{*}{$m C G B$} & F: TGTCGCCTTTAACACCACCAT \\
\hline & R: TCTGCAGCACCCGTACCAT \\
\hline \multirow[t]{2}{*}{ FSHR } & F: GAAAGTGTGACTCTATGGCTGAATAAGA \\
\hline & R: CTCATCTAGTTGGGTTCCATTGAA \\
\hline \multirow[t]{2}{*}{ LHCGR } & F: GAGCCGGGAGCATTTACAAA \\
\hline & R: TGGAAACTTTCTAATGCCTGTGTTA \\
\hline
\end{tabular}

was employed as marker for differentiating spermatogonia. Additional markers were used for meiotic and postmeiotic stages of spermatogenesis: BOULE (BOLL) and DAZL (deleted in azoospermia-like, Tung et al. (2006)). DDX4 (dead box protein 4) was used as a marker gene for germ cells and ITGB1 $(\beta$-1-integrin) as a marker for cells homing on basement membranes. Additional marker genes were selected for Sertoli and Leydig cells, such as FSH receptor (FSHR) and LHCGR (LH receptor $(L H R))$. It was previously described that $D D X 4$ is a marker for germ cells at different stages of development, and is already expressed in the fetus at 14 weeks of gestation in the marmoset (Mitchell et al. 2008); it is also expressed in the adult testis. POU5F1 and TFAP2C are stem cell markers, both are expressed in gonocyte nuclei of marmoset fetuses at 14 (POU5F1) and 17 (TFAP2C) weeks of gestation and their expression decreases with the germ cell development, until they disappear after gonocyte differentiation (Mitchell et al. 2008). KIT is a cytoplasmic marker for differentiating spermatogonia and in the marmoset testis its expression is found in the adult (von Schönfeldt et al. 1999).

Relative quantitative RT-PCR (qRT-PCR) was performed on testicular RNA from five newborn, five 8-week-old, and five adult monkeys. Primers of stem cell genes such as POU5F1, NANOG, SOX2, TFAP2C, and for differentiating early spermatogonia as KIT; of germ cells genes such as $D D X 4$ and ITGB 1; and of other germ- and somatic-cell-related genes, such as LHCGR, FSH, BOLL, DAZL, GFRA1, GPR125, NANOS, ZBTB16 (PLZF), and $m C G B$, were designed on the basis of the whole marmoset genome, which is available in the trace archive: (http://blast.ncbi.nlm.nih.gov/
Blast.cgi?PROGRAM = blastn\&BLAST_SPEC $=$ TraceArchive $\& B L A S T \_P R O G R A M S=$ megaBlast\&PAGE_TYPE $=$ BlastSearch).

The gene sequences were annotated by aligning them to the corresponding human and mouse genes; they displayed an average nucleotide homology of about $85 \%$ between marmoset and human/mouse. Primers were designed with PrimerExpress, if possible crossing exon boundaries, to yield an RNA-specific and marmoset-specific expression panel (Table 3). Primers were tested to yield a distinct, single amplicon by $2 \%$ agarose gel electrophoresis. Fidelity of the different amplicons was confirmed by DNA sequencing. For qPCR, a primer concentration optimizing run according to the Power SYBRGreen PCR Master Mix and RT-PCR Protocol from Applied Biosystems (Darmstadt, Germany), including a dissociation curve, was performed for each gene.

Briefly, $2 \mu \mathrm{g}$ testicular RNA was reverse transcribed, using random hexamers, by Superscript II (Invitrogen) to obtain CDNA; $2 \mu \mathrm{l}$ of 1:2 diluted cDNA was used for each $20 \mu \mathrm{l}$ PCR with Power SYBRGreen Master Mix (Applied Biosystems), and different primer concentrations ranging between 50 and $900 \mathrm{nM}$. The PCR program consisted of initial steps of activation and denaturation, which were run once for $10 \mathrm{~min}$ at $50{ }^{\circ} \mathrm{C}$ and $5 \mathrm{~min}$ at $95^{\circ} \mathrm{C}$ respectively followed by 40 cycles of annealing $\left(15 \mathrm{~s}\right.$ at $\left.95^{\circ} \mathrm{C}\right)$, elongation $\left(1 \mathrm{~min}\right.$ at $60^{\circ} \mathrm{C}$ ), and denaturation steps. The extent of fluorescence of the SYBRGreen dye was detected and analyzed using the ABI Prism7000 SDS software (Applied Biosystems). Each sample was assayed in triplicate and normalized to glyceraldehyde-3-phosphate dehydrogenase expression. Relative quantification was based on the $2(-\Delta \Delta C(\mathrm{~T}))$ method according to Livak \& Schmittgen (2001) using adult testicular RNA as calibrator.

\section{Statistical analysis}

Single data points represent the results from a single monkey. The difference in histological scores on testicular composition as well as numbers of cells expressing specific markers was tested by unpaired $t$-test (significance at $P<0.05$; SigmaStat Version 3.5, Erkrath, Germany). Statistically, significant changes of cell numbers are indicated by asterisks. Data on mRNA expression among the three ages were compared by one-way repeated measures ANOVA with the Holm-Sidak post hoc test. Different letters indicate significant differences of marker expression at different ages.

\section{Declaration of interest}

The authors declare that there is no conflict of interest that could be perceived as prejudicing the impartiality of the research reported.

\section{Funding}

This study was supported by the German Research Foundation by an unrestricted grant within the Research Unit 'Germ Cell Potential' (FOR 1041-GR 1547/11-1) and BMBF grant 01GN 0809/0810 entitled 'Pluripotent cells in primate testes'. 


\section{Acknowledgements}

We thank Dr Trevor G Cooper for language editing, Nicole Terwort for rqPCR analyses, Jutta Salzig and Heidi Kersebom for technical support with the immunostainings, and Martin Heuermann and Günter Stelke for animal care.

\section{References}

Ehmcke J \& Schlatt S 2006 A revised model for spermatogonial expansion in man: lessons from non-human primates. Reproduction 132 673-680. (doi:10.1530/rep.1.01081)

Ehmcke I, Luetjens CM \& Schlatt S 2005a Clonal organization of proliferating spermatogonial stem cells in adult males of two species of non-human primates, Macaca mulatta and Callithrix jacchus. Biology of Reproduction 72 293-300. (doi:10.1095/biolreprod.104.033092)

Ehmcke J, Simorangkir DR \& Schlatt S 2005b Identification of the starting point for spermatogenesis and characterization of the testicular stem cell in adult male rhesus monkeys. Human Reproduction 20 1185-1193. (doi:10.1093/humrep/deh766)

Ehmcke J, Wistuba J \& Schlatt S 2006 Spermatogonial stem cells: questions, models and perspectives. Human Reproduction Update 12 275-282. (doi:10.1093/humupd/dmk001)

Forand A, Fouchet P, Lahaye JB, Chicheportiche A, Habert R \& BernardinoSgherri J 2009 Similarities and differences in the in vivo response of mouse neonatal gonocytes and spermatogonia to genotoxic stress. Biology of Reproduction 80 860-873. (doi:10.1095/biolreprod.108. 072884)

Henke A \& Gromoll J 2008 New insights into the evolution of chorionic gonadotrophin. Molecular and Cellular Endocrinology 291 11-19. (doi:10.1016/j.mce.2008.05.009)

Kelnar CJ, McKinnell C, Walker M, Morris KD, Wallace WH, Saunders PT, Fraser HM \& Sharpe RM 2002 Testicular changes during infantile 'quiescence' in the marmoset and their gonadotrophin dependence: a model for investigating susceptibility of the prepubertal human testis to cancer therapy? Human Reproduction 17 1367-1378. (doi:10.1093/ humrep/17.5.1367)

Li LH, Donald JM \& Golub MS 2005 Review on testicular development, structure, function, and regulation in common marmoset. Birth Defects Research. Part B, Developmental and Reproductive Toxicology $\mathbf{7 4}$ 450-469. (doi:10.1002/bdrb.20057)

Livak KJ \& Schmittgen TD 2001 Analysis of relative gene expression data using real-time quantitative PCR and the $2(-$ Delta Delta $C(\mathrm{~T}))$ method. Methods 25 402-408. (doi:10.1006/meth.2001.1262)

Luetjens CM, Weinbauer GF \& Wistuba J 2005 Primate spermatogenesis: new insights into comparative testicular organisation, spermatogenic efficiency and endocrine control. Biological Reviews of the Cambridge Philosophical Society 80 475-488. (doi:10.1017/S1464793105006755)

Millar MR, Sharpe RM, Weinbauer GF, Fraser HM \& Saunders PT 2000 Marmoset spermatogenesis: organizational similarities to the human. International Journal of Andrology 23 266-277. (doi:10.1046/j.13652605.2000.00236.x)

Mitchell RT, Cowan G, Morris KD, Anderson RA, Fraser HM, Mckenzie KJ, Wallace WH, Kelnar CJ, Saunders PT \& Sharpe RM 2008 Germ cell differentiation in the marmoset (Callithrix jacchus) during fetal and neonatal life closely parallels that in the human. Human Reproduction 23 2755-2765. (doi:10.1093/humrep/den295)

Mitchell RT, Saunders PT, Sharpe RM, Kelnar CJ \& Wallace WH 2009 Male fertility and strategies for fertility preservation following childhood cancer treatment. Endocrine Development 15 101-134. (doi:10.1159/000207612)

Müller T, Fleischmann G, Eildermann K, Mätz-Rensing K, Horn PA, Sasaki E \& Behr R 2009 A novel embryonic stem cell line derived from the common marmoset monkey (Callithrix jacchus) exhibiting germ cell-like characteristics. Human Reproduction 24 1359-1372. (doi:10.1093/ humrep/dep012)

Norton AJ, Jordan S \& Yeomans P 1994 Brief, high-temperature heat denaturation (pressure cooking): a simple and effective method of antigen retrieval for routinely processed tissues. Journal of Pathology $\mathbf{1 7 3}$ 371-379. (doi:10.1002/path.1711730413)

deRooij D 1998 Stem cells in the testis. International Journal of Experimental Pathology 79 67-80. (doi:10.1046/j.1365-2613.1998. 00057.x)

Sasaki E, Suemizu H, Shimada A, Hanazawa K, Oiwa R, Kamioka M, Tomioka I, Sotomaru Y, Hirakawa R, Eto T et al. 2009 Generation of transgenic non-human primates with germline transmission. Nature $\mathbf{4 5 9}$ 523-527. (doi:10.1038/nature08090)

von Schönfeldt V, Krishnamurthy H, Foppiani L \& Schlatt S 1999 Magnetic cell sorting is a fast and effective method of enriching viable spermatogonia from Djungarian hamster, mouse, and marmoset monkey testes. Biology of Reproduction 61 582-589. (doi:10.1095/biolreprod61. 3.582)

Sharpe RM, Fraser HM, Brougham MF, McKinnell C, Morris KD, Kelnar C], Wallace WH \& Walker M 2003 Role of the neonatal period of pituitarytesticular activity in germ cell proliferation and differentiation in the primate testis. Human Reproduction 18 2110-2117. (doi:10.1093/ humrep/deg413)

Simorangkir DR, Marshall GR, Ehmcke J, Schlatt S \& Plant TP 2005 Prepubertal expansion of dark and pale type A spermatogonia in the rhesus monkey (Macaca mulatta) results from proliferation during infantile and juvenile development in a relatively gonadotropin independent manner. Biology of Reproduction 73 1109-1115. (doi:10. 1095/biolreprod.105.044404)

Tung JY, Luetjens CM, Wistuba J, Xu EY, Reijo Pera RA \& Gromoll J 2006 Evolutionary comparison of the reproductive genes, DAZL and BOULE, in primates with and without DAZ. Development Genes and Evolution 216 158-168. (doi:10.1007/s00427-005-0039-2)

Weinbauer GF, Aslam H, Krishnamurthy H, Brinkworth MH, Einspanier A \& Hodges JK 2001 Quantitative analysis of spermatogenesis and apoptosis in the common marmoset (Callithrix jacchus) reveals high rates of spermatogonial turnover and high spermatogenic efficiency. Biology of Reproduction 64 120-126. (doi:10.1095/biolreprod64.1.120)

Wistuba J, Schrod A, Greve B, Hodges JK, Aslam H, Weinbauer GF \& Luetjens CM 2003 Organization of seminiferous epithelium in primates: relationship to spermatogenic efficiency, phylogeny, and mating system. Biology of Reproduction 69 582-591. (doi:10.1095/biolreprod.103. 015925)

Wistuba J, Mundry M, Luetjens CM \& Schlatt S 2004 Cografting of hamster (Phodopus sungorus) and marmoset (Callithrix jacchus) testicular tissues into nude mice does not overcome blockade of early spermatogenic differentiation in primate grafts. Biology of Reproduction 71 2087-2091. (doi:10.1095/biolreprod.104.033431)

Wistuba J, Stukenborg JB \& Luetjens CM 2007 Mammalian spermatogenesis. Functional Development and Embryology 1 99-116.

Wu X, Schmidt JA, Avarbock MR, Tobias JW, Carlson CA, Kolon TF, Ginsberg JP \& Brinster RL 2009 Prepubertal human spermatogonia and mouse gonocytes share conserved gene expression of germline stem cell regulatory molecules. PNAS 106 21672-21677. (doi:10.1073/pnas. 0912432106)

Received 21 May 2010

First decision 25 June 2010

Accepted 20 August 2010 